\title{
Prevalence of sleep disorders in Parkinson's disease patients in two neurology referral hospitals in Ethiopia
}

\author{
Dereje Melka ${ }^{1 *}$, Abenet Tafesse', James H. Bower ${ }^{2}$ and Demeke Assefa ${ }^{3}$
}

\begin{abstract}
Background: Non motor symptoms (NMS) of Parkinson's disease (PD) are common and can be more disabling than motor symptoms. Sleep disorders can be seen in up to $98 \%$ of patients with Parkinson disease. Poor sleep quality has been associated with poverty and race, and yet there has been no prior report on sleep disorders in those with PD living in sub Saharan Africa. We wished to document the prevalence of sleep disorders in PD patients in Ethiopia.

Methods: We conducted a cross-sectional point prevalence study from July 1 to October 30, 2015 of all patients attending the neurology outpatient department in Tikur Anbessa and Zewuditu Memorial Hospitals, Addis Ababa, Ethiopia. Demographic data, clinical history and physical examination findings were collected from participants using a structured questionnaire. We used the Parkinson's disease sleep scale version two (PDSS-2) and Epworth Sleepiness Scale (ESS) to assess the sleep symptoms.

Results: Of the 155 patients surveyed, all patients reported some sleep problem. Over $43.9 \%$ of patients had a PDSS score $>18$. The median score of ESS was $9(\mathrm{IQR}=5-12)$, with 77/155 (49.7\%) of the patients having possible or definite excessive daytime somnolence. A high EDSS score significantly associated with a Hoehn \& Yahr score $\geq 4(p=0.02)$.

Conclusions: In Ethiopian PD patients, the prevalence of those with severe sleep disorders is the highest reported to date. The prevalence of possible/definite EDS is amongst the highest in the world. Further investigation into whether poverty or race explains this finding is needed.
\end{abstract}

Keywords: Parkinson's disease, Sleep disorders, Africa, Poverty

\section{Background}

The NMS of PD are frequent and can be very disabling $[1,2]$.

Sleep disorders associated with PD are one of the most common NMS and have been reported in 38 to $98 \%$ of PD patients [3]. They were first mentioned by James Parkinson himself in his famous monograph about the disease. Sleep disorders can occur before the diagnosis of PD, but become more severe and frequent as the disease stage progresses [2].

Patients with PD are at a greater risk for developing sleep disturbances than the general population. Sleep disturbances are a common but often under recognized

\footnotetext{
* Correspondence: m.dereje@yahoo.com

${ }^{1}$ Department of Neurology, Addis Ababa University School of Medicine,

P.O.Box 1176, Addis Ababa, Ethiopia

Full list of author information is available at the end of the article
}

feature of PD in clinical practice because of the absence of systematic or specific questioning by health care professionals [4].

There have been limited recent studies published on PD in sub Saharan Africa [5-12] and far fewer from Ethiopia [13, 14]. Poor sleep quality has been found to be strongly associated with poverty and race [15] and yet there have been no published data on sleep disorders in people with PD living in sub Saharan Africa. We wanted to document the prevalence of sleep disorders and their determinant factors in people living with PD in Ethiopia.

\section{Methods}

We conducted a cross-sectional point prevalence study from July 1 to October 30, 2015 of all patients attending the neurology outpatient departments in Tikur Anbessa and Zewuditu Memorial Hospitals in Addis Ababa 
University. These serve as the hospitals for the only neurology training center in Ethiopia. Inclusion criteria were patients $\geq 18$ years old diagnosed with PD using the UK Parkinson's Disease Society Brain Bank Clinical Diagnostic Criteria seen at the two referral hospitals during the study period who gave informed verbal consent for study participation. Exclusion criteria were secondary Parkinsonism or refusal of informed verbal consent. Demographic data, clinical history and physical examination findings were collected from participants using structured questionnaires in Amharic and English. We also used two data collection instruments: the Parkinson Disease Sleep Scale version- 2 (PDSS-2) [16], and the Epworth Sleepiness Scale (ESS) $[17,18]$.

The PDSS- 2 is a scale addressing 15 commonly reported symptoms associated with sleep disturbance. This scale has been shown to correlate with the Parkinson's disease Quality of Life Questionnaire (PDQ-39), the Unified Parkinson's Disease Rating Scale motor scores (UPDRSIII), and the Clinical Global Impressions Severity Score (CGI Item 1) [19-21].

The ESS is used as a subjective measure of a patient's daytime sleepiness. This scale has a list of eight situations in which patients rate their likelihood of becoming sleepy on a scale of $0-3$. Total score ranges from 0 to 24 . A score of 10-15 suggests possible excessive daytime somnolence, and a score of 16-24 suggests definite excessive daytime somnolence $[17,18]$.

The PDSS-2 and ESS were translated from English into Amharic and pilot-tested on 10 subjects. All subjects understood every question without difficulty. No re-translation was required. These subjects were not included in the study results.

Analysis was performed using SPSS/PC version 20.0 software packages for statistical analysis (SPSS). Descriptive summaries were employed to describe socio-demographic and clinical characteristics. Appropriate measures of central tendency, frequency distribution, cross tabulation, Fisher's Exact test and binary logistic regression analysis were conducted. Odds ratios and $95 \%$ confidence intervals were calculated. A $p$ value less than 0.05 was considered a statistically significant association between assessed variables.

Protocol approvals were obtained from the ethical review Committee of the Department of Neurology and the Institutional Review Board and Research and Publication Committee of the College of Health Sciences of Addis Ababa University. Informed patient consent was obtained verbally before study enrollment. Patient data was deidentified during subsequent analysis and dissemination.

\section{Results}

Out of 158 patients who presented during the study period, two refused consent and one did not fulfill the diagnostic criteria. A total of 155 subjects were included in this study: 127 (81.9\%) male: 28 (18.1\%) female. Table 1 shows the demographics of our subjects. The mean duration of symptoms, duration since PD diagnosis and duration of PD treatment were 6.37, 4.90, 4.68 yrs. respectively. All patients were taking levodopa and 23.9\% were taking trihexyphenidyl. No patient was taking other anti-parkinsonian agents (e.g. dopamine agonist, amantadine).

Table 2 shows the results of the PDSS- 2 scores. No patient had a score of zero (range 4-39). The median score was 17 (IQR 11-24). Overall, 66/155 (42.6\%) reported not having slept well $\geq 2$ days per week. 68/155 $(43.9 \%)$ scored $\geq 18$. The most frequent sleep problems

Table 1 Socio-demographic Factors

\begin{tabular}{|c|c|}
\hline Variables & Numbers (\%) \\
\hline \multicolumn{2}{|l|}{ Gender } \\
\hline Female & $28(18.1)$ \\
\hline Male & $127(81.9)$ \\
\hline \multicolumn{2}{|l|}{ Age } \\
\hline$<60$ years & $89(57.4)$ \\
\hline$\geq 60$ years & $66(42.6)$ \\
\hline \multicolumn{2}{|l|}{ Marital status } \\
\hline Never married & $6(3.9)$ \\
\hline Married & $121(78.1)$ \\
\hline Widowed & 19 (12.3) \\
\hline Divorced/separated & $9(5.8)$ \\
\hline \multicolumn{2}{|l|}{ Duration of PD symptoms in years } \\
\hline$<5$ years & $85(54.8)$ \\
\hline$\geq 5$ years & $70(45.2)$ \\
\hline \multicolumn{2}{|l|}{ Employment status } \\
\hline Employed & $44(28.4)$ \\
\hline Unemployed & $111(71.6)$ \\
\hline \multicolumn{2}{|l|}{ Educational status } \\
\hline No formal education & $48(31)$ \\
\hline Primary education & $45(29)$ \\
\hline Secondary education & $36(23.2)$ \\
\hline More than secondary education & $26(16.7)$ \\
\hline \multicolumn{2}{|l|}{ Hoehn and Yahr stage } \\
\hline Stage 1 & $37(23.9)$ \\
\hline Stage 2 & $46(29.7)$ \\
\hline Stage 3 & $44(28.4)$ \\
\hline Stage 4 & $23(14.8)$ \\
\hline Stage 5 & $5(3.2)$ \\
\hline \multicolumn{2}{|l|}{ Previous history of sleep disorder } \\
\hline Yes & $37(23.9)$ \\
\hline No & $118(76.1)$ \\
\hline
\end{tabular}


Table 2 Results of Parkinson Disease Sleep Scale Version 2

\begin{tabular}{|c|c|c|c|c|c|}
\hline Questions & $\begin{array}{l}\text { Very often (6-7 } \\
\text { days/ week) No } \\
\text { (\%) }\end{array}$ & $\begin{array}{l}\text { Often (4-5 } \\
\text { days/ week) No } \\
\text { (\%) }\end{array}$ & $\begin{array}{l}\text { Sometimes(2-3 } \\
\text { days/ week) No } \\
\text { (\%) }\end{array}$ & $\begin{array}{l}\text { Occasionally(1 } \\
\text { day/ week) No } \\
(\%)\end{array}$ & $\begin{array}{l}\text { Never } \\
\text { No (\%) }\end{array}$ \\
\hline 1. Overall did you sleep well during the last week? & $89(56.8)$ & $19(12.6)$ & $19(12.6)$ & $23(14.8)$ & $5(3.2)$ \\
\hline 2. Did you have difficulty falling asleep each night? & $6(3.9)$ & $16(10.6)$ & $25(16.1)$ & $36(23.5)$ & $\begin{array}{l}72 \\
(45.8)\end{array}$ \\
\hline 3. Did you have difficulty staying asleep? & $11(7.1)$ & $19(12.8)$ & $24(15.8)$ & $32(20.6)$ & $\begin{array}{l}69 \\
(43.9)\end{array}$ \\
\hline $\begin{array}{l}\text { 4. Did you have restlessness of legs or arms at night or in } \\
\text { the evening causing disruption of sleep? }\end{array}$ & $4(2.6)$ & $23(14.8)$ & $14(9.4)$ & $34(21.9)$ & $\begin{array}{l}80 \\
(51.3)\end{array}$ \\
\hline $\begin{array}{l}\text { 5. Was your sleep disturbed due to an urge to move your } \\
\text { arms or legs? }\end{array}$ & $5(3.4)$ & $17(11.4)$ & $20(12.9)$ & $35(22.6)$ & $\begin{array}{l}78 \\
(49.7)\end{array}$ \\
\hline 6. Did you suffer from distressing dreams at night? & $12(7.7)$ & $16(10.6)$ & $28(18.4)$ & $30(19.4)$ & $\begin{array}{l}69 \\
(43.9)\end{array}$ \\
\hline $\begin{array}{l}\text { 7. Do you suffer from distressing hallucinations at night } \\
\text { (seeing or hearing things that you are told do not exist)? }\end{array}$ & $4(2.6)$ & $10(6.7)$ & $14(9.4)$ & $27(17.4)$ & $\begin{array}{l}100 \\
(63.9)\end{array}$ \\
\hline 8. Do you get up at night to pass urine? & $58(37.6)$ & $33(21.3)$ & $23(14.8)$ & $26(16.8)$ & $\begin{array}{l}15 \\
(9.4)\end{array}$ \\
\hline $\begin{array}{l}\text { 9. Did you feel uncomfortable at night because you were } \\
\text { unable to turn around in bed or move due to immobility? }\end{array}$ & $11(7.4)$ & $23(14.8)$ & $24(15.5)$ & $45(29.3)$ & $\begin{array}{l}52 \\
(32.9)\end{array}$ \\
\hline $\begin{array}{l}\text { 10. Did you feel pain in your arms or legs which wake you } \\
\text { from sleep at night? }\end{array}$ & $2(2.6)$ & $14(9.0)$ & $25(14.2)$ & $36(24.5)$ & $\begin{array}{l}76 \\
(49.7)\end{array}$ \\
\hline $\begin{array}{l}\text { 11. Did you have painful muscle cramps in your arms or legs } \\
\text { which wake you from sleep at night? }\end{array}$ & $2(1.6)$ & $14(9.0)$ & $19(12.3)$ & $48(31.3)$ & $\begin{array}{l}72 \\
(45.8)\end{array}$ \\
\hline $\begin{array}{l}\text { 12. Did you wake early in the morning with painful } \\
\text { posturing of arms or legs? }\end{array}$ & $4(2.6)$ & $8(5.4)$ & $17(11.4)$ & $24(15.5)$ & $\begin{array}{l}102 \\
(65.1)\end{array}$ \\
\hline 13. On waking did you experience tremor? & $6(3.9)$ & $20(12.9)$ & $20(12.9)$ & $44(28.7)$ & $\begin{array}{l}65 \\
(41.6)\end{array}$ \\
\hline $\begin{array}{l}\text { 14. Did you feel tired and sleepy after waking in the } \\
\text { morning? }\end{array}$ & $9(5.8)$ & $17(11.3)$ & $25(16.4)$ & $40(25.8)$ & $\begin{array}{l}64 \\
(40.6)\end{array}$ \\
\hline $\begin{array}{l}\text { 15. Did you wake up at night due to snoring or difficulties } \\
\text { with breathing? }\end{array}$ & $9(5.8)$ & $9(5.8)$ & $13(8.7)$ & $26(16.8)$ & $\begin{array}{l}97 \\
(62.9)\end{array}$ \\
\hline
\end{tabular}

(defined as $\geq 2$ nights per week) were due to nocturia (73.5\%), followed by difficulty with mobility in bed (37.4\%), distressing dreams (36.1\%) and sleep maintenance insomnia (34.8\%).

Univariate analysis was performed to determine factors associated with a PDSS-2 score $\geq 18$. A previous history of sleep disturbance before $\mathrm{PD}^{-}$motor symptoms (OR 3.54; 95\% CI 1.61-7.76, $p=0.001)$ and unemployment (OR 2.27; 95\% CI 1.07-4.79, $p=0.023$ ) both associated with a high PDSS-2 score. However a logistic regression analysis didn't show a significant association with a previous history of sleep disturbance, age, gender, levodopa or trihexyphenidyl use, marital, educational or employment status.

The results of the ESS are shown in the Fig. 1. The median score was 9 (IQR 5-12). 73/155 (47.1\%) of the patients had possible or definite excessive daytime somnolence. An EDSS score of $\geq 10$ associated with an H\&Y score $\geq 4(p=0.02)$. There was no statistically significant association between age, gender, PD duration, levodopa or trihexyphenidyl use, marital status, educational status or employment status with daytime sleepiness (EDSS score $\geq 10$ ).

On univariate analysis, there was a statistically significant association between ESS total score $\geq 10$ with only two variables of the PDSS-2: PD patients waking up at night due to snoring or difficulties with breathing (OR 2.87; 95\% CI 1.25-6.60, $p=0.015$ ) and getting up at night to pass urine (OR 2.3; 95\% CI 1.08-4.92, $p=$ 0.042). The other items of the PDSS-2 were not associated with a high ESS score.

\section{Discussion}

We found that all of our Ethiopian PD patients reported some sleep problem, with a large minority (42.6\%) reporting not sleeping well $>2$ nights per week. One community based study from Norway reported that $60 \%$ of their PD patients had sleep problems [22].

Compared to patients from Germany [23] and the United Kingdom [24] in terms of overall sleep disturbance, there was a higher percentage of Ethiopian patients with a severe sleep disorder. Trenkwalder et al. [16] 


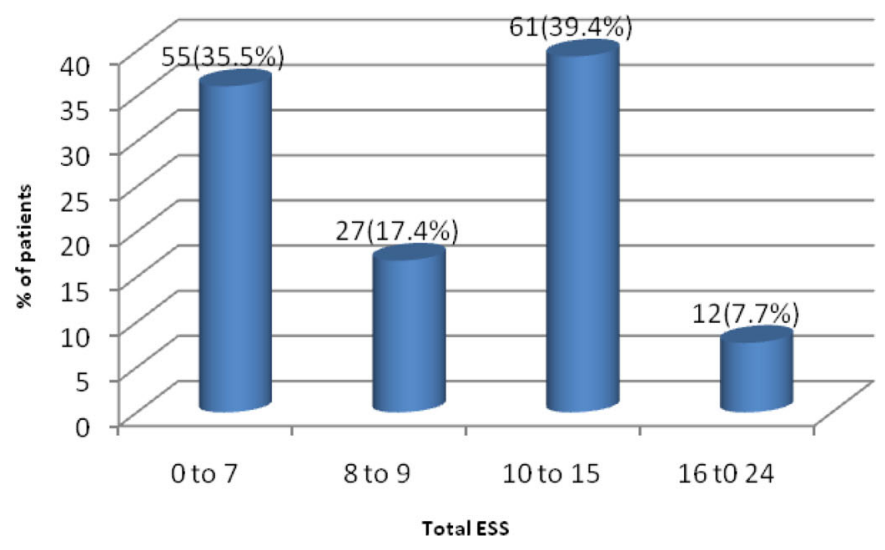

- percent of patients

*0-7 Unlikely to be abnormally sleepy

8-9 Average amount of daytime sleepiness

10-15 Possible excessive daytime sleepiness

16-24 Excessive daytime sleepiness

Fig. 1 Frequency distribution of total Epworth sleepiness scale (ESS) scores*

reported a mean PDSS score of 16.5- similarly to our mean score of 18.3 (median 17). However, they found that only $6.3 \%$ of their patients had a score $\geq 30$, whereas in our population, $23.2 \%$ of our patients had a score $\geq 30$ [16].

Nocturia and mobility difficulties were the most frequent sleep problems in our population. Other authors have found similar issues. Nocturia was reported by $62 \%$ of patients in the NMS Quest Study [25]. Adler et al. reported that $80 \%$ of patients with PD have two or more episodes of nocturia per night, and 33\% urinate at least three times per night [26]. Lees and his colleagues [24] have reported nocturnal disturbances in 215 of 220 PD patients, including nocturia (79\%) and difficulty turning over in bed (65\%).

Over a third of our patients (36.1\%) reported having distressing dreams. Nightmares have been reported in $30 \%$ of patients with PD and are correlated with disease severity and levodopa dose [27].

Insomnia occurs in about $30 \%$ of patients with PD. [27] Patients often develop a sleep pattern marked by excessive napping during the day and wakefulness at night [2]. We found sleep onset insomnia $\geq 2$ days/week in 47 PD patients (30.3\%) and sleep maintenance insomnia $\geq 2$ days/week in 54 PD patients (34.9\%). This is comparable with one study from India. Kumar et al. reported the prevalence of insomnia in PD patients were 30\% [27].

Excessive day-time sleepiness (EDS) is a common complaint of patients with PD. [28, 29] It can occur early in PD [30], and may predate the diagnosis [31]. We found that $47.1 \%$ of our patients had possible or definite EDS. This is one of the highest rates reported in the world. Possible or definite EDS (ESS $>10$ ) was seen in $15.5 \%$ of PD patients in Norway, 33\% in Austria, $40.6 \%$ in New York USA, 46.2\% in France, and 50.2\% in Houston,USA [3, 32-35]. Adler et al. identified that advanced disease stage and age predicted EDS [26]. We also found an association between higher PD stage and higher ESS scores.

The number of patients using trihexyphenidyl is high (23.9\%) in our study. This drug is not commonly used in western countries. However, due to cost, levodopa/carbidopa and trihexyphenidyl are the only available medications to treat PD symptoms. Therefore, trihexyphenidyl is often the first medication prescribed. Although its anticholinergic property may affect sleep, we did not find an association between trihexyphenidyl use and a higher level of sleep disturbance.

We found that high ESS scores associated with patients reporting both nocturia and breathing difficulties/ snoring on the PDSS. OSA is defined as intermittently absent or reduced airflow during sleep despite respiratory effort. A study from Mexico City on 120 PD patients reported obstructive sleep apnea (OSA) in 39\% of patients [36]. We found $57 \mathrm{PD}$ patients (36.8\%) reporting OSA symptoms at least 1 day per week. A study from France on 100 patients also reported 27\% of PD patents were having obstructive sleep apnea [37].

One limitation of our study is that we did not assess body mass index (BMI) in our patients. High BMI is a major contributor of OSA. However, the prevalence of obesity in Ethiopia is very low. A World Bank report in June 2017 estimated the prevalence of obesity in Ethiopia to be less than 5\% [38]. This was much lower than the other countries [38]. A summary report on risk factors for non-communicable diseases in Ethiopia from 2016 reported the prevalence of obesity $(\mathrm{BMI}>30)$ for male and female Ethiopians was 0.5 and $2 \%$ respectively 
[39]. Another study from 2011 estimated the prevalence of obesity to be $2.1 \%$ for males and $10.2 \%$ for females. Although this study reported a higher rate among females than the others, this rate is still low, and most of our PD patients were male [40].

Another limitation of our study was that we did not assess for anxiety/depression. One study found an association between depression and sleep disorders [3], while others did not assess for depression or found no association [16, 23, 24, 31-34]. There is no validated depression scale for PD patients in Ethiopia, so we felt this was out of scope for this study.

Our study had other limitations. In Ethiopia there is no polysomnography (PSG), the gold standard for evaluating sleep disorders. Therefore, we had to rely on the PDSS-2. The PDSS is a subjective semi quantitative scale, which attempts to provide a holistic and clinical assessment of the complex etiology of sleep problems in Parkinson's disease.

One other significant limitation of our study was our inability to assess for REM Sleep Behavior Disorder (RBD). Only 15 (9.7\%) of our patients attended their clinic visits with a reliable sleep partner, so we could not use a questionnaire to evaluate for RBD, and of course, did not have access to PSG. In one study of 19 patients with PD, 47\% met the diagnostic criteria of RBD based on PSG recordings, but only $33 \%$ of these cases were detected by a questionnaire [26]. We suspect that our percent of patients with Sleep Disorders would have been higher had we had a reliable way to assess for RBD.

\section{Conclusions}

We found a higher percentage of Ethiopian patients with a high PDSS-2 score ( $>18)$ than reported in other populations. Our patients also had one of the highest rates of EDS in the world. We cannot conclude from our data that this is due to poverty, but further investigation into this question is warranted.

\section{Abbreviations}

Cl: Confidence Interval; EDS: Excessive Daytime Sleepiness; ESS: Epworth Sleepiness Scale; IQR: Inter Quartile Range; NMS: Non Motor Symptoms; PD: Parkinson 's Disease; PDSS-2: Parkinson's Disease Sleep Scale Version 2

\section{Acknowledgments}

Not applicable.

\section{Authors' contributions}

Dr. DM data acquisition, analysis, interpretation, review and critique. Dr. AT analysis, interpretation, review and critique. Dr. JHB analysis, interpretation, review and critique. Dr. DA analysis, interpretation, review and critique. Dr. DM also participated in project execution and writing first draft on manuscript preparation. All authors' read and approved the final version of the manuscript.

\section{Funding}

This study was supported by the Department of Neurology, Addis Ababa University School of Medicine. It did not receive any specific grant from funding agencies in the public, commercial, or not-for-profit sectors.

\section{Availability of data and materials}

The data is on a password protected computer of Dr. DM. The datasets used and analyzed during the current study are available from the corresponding author upon reasonable request.

\section{Ethics approval and consent to participate}

Protocol approvals were obtained from the ethical review Committee of the Department of Neurology and the Institutional Review Board and Research and Publication Committee of the College of Health Sciences of Addis Ababa University. Informed patient consent was obtained verbally before study enrollment, which was approved by both the Department of Neurology and the Institutional Review Board and Research and Publication Committee of the College of Health Sciences. Patient data was deidentified during subsequent analysis and dissemination.

\section{Consent for publication}

All authors consented.

\section{Competing interests}

The authors declare that they have no competing interests.

\section{Author details}

${ }^{1}$ Department of Neurology, Addis Ababa University School of Medicine, P.O.Box 1176, Addis Ababa, Ethiopia. ${ }^{2}$ Department of Neurology, Mayo Clinic School of Medicine, 200 First St SW, Rochester, MN, USA. ${ }^{3}$ Department of Health Service Management and Reproductive Health, School of Public Health College of Health Sciences, Addis Ababa University, Addis Ababa, Ethiopia.

Received: 21 December 2018 Accepted: 23 July 2019

Published online: 22 August 2019

\section{References}

1. Parkinson J. An essay on the shaking palsy (London, 1817). J Neuropsychiatry Clin Neurosci. 2002;14(2):223-36. discussion 222.

2. Zesiewicz T, Hauser R. Medical treatment of motor and nonmotor features of parkinson's disease. Continuum:Lifelong Learning Neurol. 2007;13(1):12-38.

3. Tandberg E, Larsen J, Karlsen K. Excessive daytime sleepiness and sleep benefit in Parkinson's disease: A community-based study. Mov Disord. 1999; 14:922-7.

4. Dhawan V, Healy DG, Pal S, Chaudhuri KR. Sleep-related problems of Parkinson's disease. Age Aging. 2006:35:220-8.

5. Dotchin CL, Msuya O, Kissima J, Massawe J, Mhina A, Moshi A, Aris E, Jusabani A, Whiting D, Masuki G, Walker RW. The prevalence of Parkinson's disease in rural Tanzania. Mov Disord. 2008;23(11):1567-72.

6. Dotchin C, Jusabani A, Walker R. Three year follow up of levodopa treatment in a prevalent cohort of patients with Parkinson's disease in Hai. Tanzania J Neurol. 2011;258(9):1649-56.

7. Mshana G, Dotchin CL, Walker RW. "We call it the shaking illness": perceptions and experiences of Parkinson's disease in rural northern Tanzania. BMC Public Health. 2011;11:219.

8. Okubadejo NU, Bower JH, Rocca WA, Maraganore DM. Parkinson's disease in Africa: a systematic review of epidemiological and genetic studies. Mov Disord. 2006;21(12):2150-6

9. Rochester L, Rafferty D, Dotchin C, Msuya O, Minde V, Walker R. Rehabilitation in Parkinson's disease: the effect of cueing therapy on single and dual-task gait in a drug naïve population in the Hai district of northern Tanzania. Mov Disord. 2010;25(7):906-11.

10. Akinyemi R. Epidemiology of parkinsonism and Parkinson's disease in subSaharan Africa: Nigerian profile. J Neurosci Rural Pract. 2012;3(3):233-4.

11. Okubadejo NU, Ojo OO, Oshinaike OO. Clinical profile of parkinsonism and Parkinson's disease in Lagos. Southwestern Nigeria BMC Neurol. 2010;10:1.

12. Akinyemi RO, Okubadejo NU, Akinyemi JO, Owolabi MO, Owolabi LF, Ogunniyi A. Cognitive dysfunction in Nigerians with Parkinson's disease. MovDisord. 2008;23:1378-83.

13. Haimanot R. Parkinsons disease in Ethiopia - a prospective study of 70 patients. East Afican Med J. 1985;62(8):571-9.

14. Bower J, Teshome M, Melaku Z, Zenebe G. Frequency of movement disorders in an Ethiopian University practice. Mov Disord. 2005;20:1209-13. 
15. Patel NP, Grandner MA, Xie D, Branas CC, Gooneratne N. "sleep disparity" in the population: poor sleep quality is strongly associated with poverty and ethnicity. BMC Public Helath. 2010;10:475.

16. Trenkwalder C, Kohnen R, Högl B. Parkinson's disease sleep scale-validation of the revised version PDSS-2. Mov Disord. 2011;26(4):644-52.

17. Johans MW. A new method for measuring daytime sleepiness: Epworth Sleepiness Scale (ESS). Am Sleep Med. 1991;14(6):540-5.

18. Kumar S, Bhatia M, Behari M. Excessive day time sleepiness in Parkinson's disease as assessed by Epworth sleepiness scale (ESS). Sleep Med. 2003;4:339-42.

19. Hagell P, Nilsson M. The 39-item Parkinson's Disease Questionnaire (PDQ-39). Ther Adv Neurol Disord. 2009;2(4):205-14.

20. Fahn S, Elton RL. UPDRS program members. Unified Parkinsons disease rating scale. In: Fahn S, Marsden CD, Goldstein M, Calne DB, editors. Recent developments in Parkinsons disease, vol. 2. Florham Park: Macmillan Healthcare Information; 1987. p. 153-63.

21. Chaudhuri KR, Pal S, Di Marco A, Whately-Smith C, Bridgman K, Mathew R, Pezzela FR, Forbes A, Högl B, Trenkwalder C. The Parkinson's disease sleep scale: a new instrument for assessing sleep and nocturnal disability in Parkinson's disease. J Neurol Neurosurg Psychiatry. 2002;73:629-35.

22. Tandberg E, Larsen JP, Karlsen KH. A community-based study of sleep disorders in patients with Parkinson disease. Mov Disord. 1990;5:28-285.

23. Smith MC, Ellgring $H$, Oertel WH. Sleep disturbances in Parkinson's disease patients and spouses. J Am Geriatric Soc. 1997 Feb;45(2):194-9.

24. Lees AJ, Blackburn NA, Campbell VL. The nighttime problems of Parkinson's disease. Clin Neuropharmacol. 1988;11(6):512-9.

25. Martinez-Martin P, Schapira A, Stocchi F, Sethi K, Odin P, MacPhee G, et al. Prevalence of nonmotor symptoms in Parkinson's disease in an international setting: study using nonmotor symptoms questionnaire in 545 patients. MovDisord. 2007;22:1623-9.

26. Adler CH, Thorpy MJ. Neurology. 2005;64(Suppl 3):S12-20

27. Kumar S, Bhatia M, Behari M. Sleep disorders in Parkinson's disease. MovDisord. 2002;17:775-81.

28. Chaudhuri K. Nocturnal symptom complex in PD and its management. Neurology. 2003;61(Suppl. 3):S17-23.

29. Garcia-Borreguero D, Larosa O, Bravo M. Parkinson's disease and sleep. Sleep Med Rev. 2003:7:115-29.

30. Fabrbrini G, Barbanti P, et al. CAe Excessive daytime sleepiness in de novo and treated Parkinson's disease Mov Disord 2002;17:1026-1030.

31. Abbott R, Ross G, White L. Excessive daytime sleepiness and the future risk of Parkinson's disease. MovDisord. 2005;20(Suppl. 10):S101 (P 341).

32. Hogl B, Seppi K, Brandauer E, Glazl S, Frauscher B et al. Increased daytime sleepiness in Parkinson's disease: a questionnaire survey. MovDisord 2003 18(3): 319-323.

33. Brodsky MA, Godbold J, Roth T, Olanow CW. Sleepiness in Parkinson's disease:a controlled study. MovDisord. 2003;18(6):668-72.

34. De Cock VC, Bayard S, Jaussent I, Charif M, Grini M, et al. Daytime sleepiness in PArkinon's disease: a reappraisal. PLoS One. 2014;9(9):e107278.

35. Ondo WG, DAt Vuong K, Khan H, Atassi F, Kwak C, Jancovic J. Daytime sleepiness and other sleep disorders in PArkinson's disease. Neurology 2001 57(8):1302-1306.

36. Vanessa A, Mayela R, Azyadeh C, et al. Prevalence and correlates of sleep disorders in parkinson's disease. ArqNeuropsiquiartr. 2015;73903:241-5.

37. Val'erie C, Mahar A, Samaranda L, et al. Is obstructive sleep apnea a problem in parkinson's disease. Sleep Med. 2010;11:247-2520.

38. Htenas AM, Tanimichi-Hoberg Y, Brown L. An overview of links between obesity and food systems: implications for the agriculture GP agenda (English). Washington, DC: World Bank Group; 2017. http://documents. worldbank.org/curated/en/222101499437276873.

39. Ethiopian Public Health Institute in collaboration with World Health Organization. A summary report on STEPs survey on risk factors for noncommunicable disease and prevalence of selected NCDs in Ethiopia. Addis Ababa; 2016. http://www.gov.

40. Tran A, Gelaye B, Girma B, et al. Prevalence of Metabolic Syndrome among Working Adults in Ethiopia, AGE-Hindawi Access to Research. Int J Hypertens. 2011:8.

\section{Publisher's Note}

Springer Nature remains neutral with regard to jurisdictional claims in published maps and institutional affiliations.

\section{Ready to submit your research? Choose BMC and benefit from:}

- fast, convenient online submission

- thorough peer review by experienced researchers in your field

- rapid publication on acceptance

- support for research data, including large and complex data types

- gold Open Access which fosters wider collaboration and increased citations

- maximum visibility for your research: over $100 \mathrm{M}$ website views per year

At BMC, research is always in progress.

Learn more biomedcentral.com/submissions 